\title{
Mechanism-based Treatment in Tuberous Sclerosis Complex
}

\author{
Kristina Jülich, M.D. and Mustafa Sahin, M.D., Ph.D. \\ Department of Neurology, F.M. Kirby Center for Neurobiology, Boston Children's Hospital, \\ Harvard Medical School, Boston, MA, 02115 USA
}

\begin{abstract}
Background-Tuberous Sclerosis Complex is a genetic multi-system disorder that affects the brain in almost every patient. It is caused by a mutation in the TSC1 or TSC2 genes, which regulate mTOR, a key player in control of cellular growth and protein synthesis. The most frequent neurologic symptoms are seizures, which occur in up to $90 \%$ of patients and are often intractable, followed by autism spectrum disorders, intellectual disability, ADHD and sleep problems. Conventional treatment has frequently proven insufficient for neurologic and behavioral symptoms, particularly seizure control. This review focuses on the role of TSC/mTOR in neuronal development and network formation, and recent mechanism-based treatment approaches.

Methods-We performed a literature review to identify ongoing therapeutical challenges and novel strategies.

Results-To achieve a better quality of life for many patients, current therapy approaches are directed at restoring dysregulated mTOR signaling. Animal studies have provided insight into aberrant neuronal network formation caused by constitutive activation of the mTOR pathway, and initial studies in TSC patients using MR diffusion tensor imaging and EEG support a model of impaired neuronal connectivity in TSC. Rapamycin, an mTOR inhibitor, has been used successfully in $T s c$-deficient mice to prevent and treat seizures and behavioral abnormalities. There is recent evidence in humans of improved seizure control with mTOR inhibitors.
\end{abstract}

Conclusions-Current research provides insight into aberrant neuronal connectivity in TSC and the role of mTOR inhibitors as a promising therapeutical approach.

\section{Keywords}

TSC; rapamycin; neuronal connectivity; mTOR

\section{TSC background}

Tuberous sclerosis complex (TSC) is a genetic multi-system disorder that has an impact on many organ systems by causing growth of benign tumors, so-called hamartomas. As brain, skin, kidneys, heart, liver, lungs, and less frequently retina, gingiva, bones and gastrointestinal tract can be affected, TSC patients require coordinated care of many specialties. Revised diagnostic criteria were recently published in this journal ${ }^{1}$.

\footnotetext{
(c) 2013 Elsevier Inc. All rights reserved.

Correspondence to: Mustafa Sahin, M.D., Ph.D, Boston Children's Hospital, Dept. of Neurology, 300 Longwood Avenue CLS13074, Boston, MA 02115 - USA, Phone: 1-617-919-4518, Fax: 1-617-730-0279, mustafa.sahin@ childrens.harvard.edu.

Publisher's Disclaimer: This is a PDF file of an unedited manuscript that has been accepted for publication. As a service to our customers we are providing this early version of the manuscript. The manuscript will undergo copyediting, typesetting, and review of the resulting proof before it is published in its final citable form. Please note that during the production process errors may be discovered which could affect the content, and all legal disclaimers that apply to the journal pertain.
} 
More than $90 \%$ of patients develop neurological symptoms such as epilepsy, autism spectrum disorders (ASDs), intellectual disability, attention deficit/hyperactivity disorder (ADHD), anxiety, sleep disorders, and other behavioral problems, referred to as 'TAND' (TSC-associated neuropsychiatric disorders). TAND cause a significant disease burden on patients and their families. This review focuses on the molecular mechanisms that underlie its neurologic symptoms and discusses current treatment approaches and targeted therapeutic strategies.

TSC is caused by a mutation of either the TSC1 gene, located on chromosome 9q34, or the TSC2 gene, located on chromosome $16 \mathrm{p} 13.3^{2,3}$. It occurs with a frequency of $1: 6,000^{4}$. A heterozygous mutation of either gene leads to loss of their respective gene products, hamartin (TSC1) and tuberin (TSC2). A mutation can be found in $85 \%$ of patients, and more than 1500 mutations have been shown to cause TSC up to date (Tuberous Sclerosis Database, http://chromium.liacs.nl/LOVD2/TSC/home.php). 30\% of these mutations are inherited in an autosomal dominant fashion, $70 \%$ are de novo mutations, resulting in a disease with remarkable inter-individual phenotypic variability. In general, TSC2 mutations occur more frequently de novo and result in a more severe phenotype compared to TSC1 mutations, but genotype-phenotype analyses have failed to show further correlations, possibly due to the large number of mutations ${ }^{5}$.

\subsection{Neurologic Manifestations}

The central nervous system is involved in the vast majority of TSC patients. MRI imaging of the brain frequently shows structural abnormalities such as cortical tubers, and subependymal nodules (SEN), which can evolve into subependymal giant cell astrocytomas (SEGAs).

Tubers are focal malformations of embryonal cortical development. They are localized at the subcortical junction zone and are characterized by disorganized lamination and giant cells expressing markers of neuronal and glial differentiation, suggesting a differentiation defect of early progenitor cells ${ }^{6-8} .80-90 \%$ of TSC patients have tubers, with tuber counts ranging between 5-50 with an average count of $18.8^{9}$.

Subependymal nodules are small nodules along the lateral ventricle walls. In 5-20\% of TSC patients, SENs give rise to SEGAs, slow growing tumors with a mixed glioneuronal phenotype. They tend to be larger compared to SENs, occur near the foramen of Monroe, and have the potential to cause obstructive hydrocephalus. It has been suggested that SENs and SEGAs originate from a neural stem/progenitor cell population ${ }^{8,10}$.

Until recently, these pathological changes were thought to be responsible for the neurological phenotype of TSC patients. Current studies have suggested that subtler microscopic changes such as aberrant white matter connectivity, which cannot be visualized with regular MR imaging techniques, play a role in causing cognitive deficits, behavioral problems, ASD and epilepsy.

TSC is one of the most frequent genetic causes of epilepsy. Up to $90 \%$ of TSC patients develop seizures, most of them in infancy, which poses a considerable impact on health and quality of life, as seizures in TSC are difficult to treat with conventional antiepileptic drugs. At least one third of patients develop refractory epilepsy. Early onset of seizures is associated with an increased risk of behavioral problems, intellectual disability and reduced quality of life (reviewed in ${ }^{11}$ ). $50 \%$ have infantile spasms as the initial seizure manifestation. Complex partial seizures are the most frequent seizure type later in life, although any other form of seizure can be present as well. 
The mechanisms by which TSC causes epilepsy is unclear. Tubers and the perituberal cortex have long been associated with epilepsy ${ }^{12,13}$. Recent studies suggest a multifactorial evolution, since epileptiform discharges can also occur in areas without tubers, and TSC patients without tubers can have epilepsy ${ }^{14}$. Vigabatrin is the mainstay of therapy for earlyonset seizures in TSC patients, and is used as a first-line treatment for infantile spasms as well as focal seizures before the age of one year. It has been shown to be effective against infantile spasms in up to $95 \%$ of children with TSC ${ }^{15}$. Vigabatrin elevates GABA levels by irreversible inhibition of the GABA transaminase. Its exact mechanism of action in TSC is unclear, although a recent study suggests that vigabatrin inhibits the mTOR pathway in mouse models ${ }^{16}$.

A wide range of cognitive and behavioral problems are common in TSC. ADHD is frequently present in patients with TSC, with a rate of 50\%, comparable to the prevalence of ASD in TSC ${ }^{17-19}$. There is controversy about the use of stimulants such as methylphenidate, as they may lower the seizure threshold, although a recent meta-analysis found no difference in seizure rates between patients treated with placebo, methylphenidate or atomoxetine ${ }^{20}$. In addition, adult patients with TSC have higher rates of psychiatric comorbidities such as mood disorders, anxiety, obsessive-compulsive behavior, and alcoholism $^{21-23}$.

Intellectual disability has a prevalence of $40-50 \%$ in TSC. $30 \%$ are severely affected with IQs in the very low range, and 70\% have IQs in the normal, yet slightly left-shifted range. Still, specific impairments of memory, attention, or executive skills are common even in patients with normal intelligence ${ }^{24}$. Early-onset epilepsy, refractory seizures and autism are associated with poor cognitive outcome ${ }^{25,26}$.

Sleep disturbances are a common problem in TSC and affect up to $60 \%$ of children and $30 \%$ of adults ${ }^{25,27}$. Polysomnography shows disorganized sleep with reduced REM sleep, frequent awakenings and sleep instability even in the absence of nocturnal seizures ${ }^{28}$. In addition, seizures and treatment with antiepileptic drugs may affect sleep as well.

TSC is one of the major genetically identifiable causes of ASD. Up to 50\% of patients have ASD, compared to $1 \%$ of the general population. TSC accounts for $1-4 \%$ of all autism cases, and has a male-to-female ratio of 1:1, compared to 4:1 in the general population. Most TSC patients with autism also have epilepsy. The incidence of epilepsy in autistic patients without TSC is $30 \%$, raising the question whether epilepsy, especially early-onset seizures and infantile spasms, predispose to autism. Growing evidence suggests ASDs to be caused by abnormal neuronal connectivity, with symptoms arising as a result of 'local overconnectivity and long-distance under-connectivity' ${ }^{29,30}$ (discussed below).

\subsection{The TSC signaling pathway}

mTOR, a kinase that integrates multiple signals to regulate cellular growth and translation, has been implicated in many functions of the developing as well as mature central nervous system. Axon growth and specification, as well as proper synapse development and synaptic plasticity, require the mTOR pathway (reviewed in ${ }^{31}$ ). mTOR is activated in response to hormones, mitogens, amino acids, stress and energy, and functions within two distinct multiprotein complexes, mTORC1 and mTORC2. The main components of mTORC1 are the proteins mTOR, raptor and mLST8. It mediates control of cell size and protein synthesis through regulation of translation initiation via phosphorylation of its substrates S6K1 and $4 \mathrm{E}-\mathrm{BP} 132,33$. In contrast, the main components of mTORC2 are mTOR, rictor and mLST8. Its function is much less understood, but it appears to be involved in cytoskeleton organization ${ }^{34,35}$. TSC1 and TSC2 proteins function as a heterodimeric complex to inhibit mTOR signaling by regulating a small GTP-binding protein, Rheb (Ras homolog enriched in 
brain), which acts as an mTOR activator (Figure 1). The TSC1/TSC2 complex is activated by low cellular energy levels via AMP Kinase. Mutation of either TSC1 or TSC2 alone is sufficient to disrupt the complex and disturb its function, leading to constitutive activation of the mTOR pathway (for a review of the mTOR pathway, see ${ }^{36}$ ).

Although data on mTOR signaling in the CNS of TSC patients is limited to samples mostly obtained during epilepsy surgery, increased constitutive phosphorylation levels of mTOR pathway substrates have been identified in tubers ${ }^{37-39}$, confirming in vitro models with in vivo data.

\section{Inhibition of neuronal connectivity}

Although many studies have tried to correlate tuber number and location with the severity of CNS involvement, the question has been raised whether microscopic structural changes rather than larger brain malformations such as tubers account for neurologic symptoms in TSC patients. Seizures, autism and intellectual disability can occur in patients irrespective of their tuber burden, while others with a high tuber count may have little or no neurological deficits. The fact that TSC rodent models develop seizures and behavioral abnormalities in the absence of gross structural brain abnormalities supports this hypothesis. Neuronal network development is a complex and highly regulated process that requires multiple steps to acquire proper axon, dendrite and synapse morphology. Failure of axonal growth, specification and guidance, synapse formation, myelination or circuitry results in impaired neuronal connectivity.

Information transmission and processing in the CNS requires the formation of polarized neurons with axons transmitting, and dendrites receiving signals. This process is called axon specification. Interestingly, components of the Tsc/mTOR pathway appear to be preferentially expressed in nascent axons during early neuronal development ${ }^{40,41}$. Neuronal loss of $T s c 1$ or $T s c 2$ in a rat hippocampal tissue culture model resulted in multiple ectopic axons and failure to develop into polarized cells in vitro. On the other hand, overexpression of Tsc1 and Tsc2 in rat hippocampal neurons lead to axonal loss 41,42 . Interestingly, the formation of ectopic axons in Tscl-deficient neurons was rescued by treatment with the mTOR inhibitor rapamycin. TSC/mTOR pathway is also important for proper guidance of axons. Local protein synthesis has been shown to be involved in growth cone dynamics, and components of the mTOR pathway are active in growth cones ${ }^{43}$. Tsc 2 haploinsufficiency in mice caused aberrant retinogeniculate projections in vivo, and in Drosophila, loss of Tscl in the developing retina disrupted axon guidance in a similar fashion 44,45 .

With conventional MR imaging techniques, white matter mostly appears normal in TSC patients. However, diffusion tensor imaging (DTI), which is designed to detect white matter tract abnormalities, has contributed to the findings of aberrant connectivity in TSC. Initial studies found abnormal ADC (apparent diffusion coefficient, a measure of total diffusion), FA (fractional anisotropy, a measure of diffusion directionality), and RD (radial diffusivity, measuring diffusion perpendicular to axon tracts) values adjacent to cortical tubers and within epileptic zones. Later reports also showed DTI changes in other areas such as the corpus callosum in TSC patients compared to controls ${ }^{46-53}$. Further support for white matter irregularities derives from rodent models, where immunostaining of mouse brains with conditional neuronal and glial $T s c 1$ or glial $T s c 2$ knockout showed myelination defects and resulted in severe seizures and early death of the animals ${ }^{54-56}$.

Activity-dependent changes in synapse function such as Long Term Depression (LTD) and Long Term Potentiation (LTP) are presumed to be major mechanisms of learning and memory. The TSC/mTOR pathway plays a role in synapse plasticity through the regulation 
of protein translation of protein involved in late phase LTP ${ }^{57}$. Hippocampal neurons of $T s c 2^{+/-}$rats showed alterations in synapse plasticity in response to high-frequency tetanization, as LTP and LTD were significantly impaired compared to wild type controls ${ }^{58}$, although these rats do not display obvious deficits in learning and memory ${ }^{59}$. Likewise, postnatal hippocampal deletion of $T s c l$ in mice abolished protein synthesis-dependent metabotropic glutamate receptor (mGluR)-LTD, while a protein synthesis-independent form of NMDA receptor-mediated LTD remained unchanged ${ }^{60}$. Interestingly, $T s c 2^{+/-}$mice do have disrupted hippocampal-dependent functions such as impaired spatial learning and contextual discrimination in the absence of seizures 61 .

In summary, multiple studies have shown involvement of the mTOR pathway in many steps of neuronal development and maturation, and a failure of proper network formation with mTOR dysregulation. Increasing evidence suggests that TSC is a disorder of impaired neuronal connectivity in the brain caused by aberrant mTOR pathway signaling (Figure 2).

\section{TSC as a model for autism}

ASDs are characterized by impaired social interaction, communication deficits and behavioral problems. TSC is one of the most frequently identified monogenic causes of autism and a promising model to study its pathogenetic mechanism. Autism is a complex disorder, and animal models are only recently emerging. Although several TSC animal models display behavioral abnormalities, few researchers so far have reported autism-like features in their animals. A likely explanation is the fact that many of these knockout mice have frequent and severe seizures and die early on, obscuring behavioral studies. However, mice either overexpressing a dominant-negative form of Tsc2, or those bearing heterozygous deletion of $T s c 1$, appear to have impaired social interactions 62,63 .

Recent studies have suggested both syndromic and non-syndromic ASD to be a "developmental disconnection syndrome" caused by aberrant neuronal network formation ${ }^{29}$. A consistent finding in human post-mortem ASD studies is a loss of cerebellar Purkinje cells (PC), suggesting the cerebellum to be involved in ASD pathogenesis. Recently, cerebellum-specific TSC mouse models have been created to model ASD. Homozygous deletion of $T s c 1$ or $T s c 2$ in PC caused cell death in the PC layer with reduced excitability of the Tscl-deficient PC. These mice displayed an autism-like phenotype with social impairment, restrictive behavior, and abnormal vocalizations in the absence of seizures and brain malformations such as tubers ${ }^{64,65}$.

Further evidence for autism as a connectivity disorder comes from imaging studies designed to evaluate white matter tracts. TSC patients with ASD had abnormalities of corpus callosum projections on DTI imaging, whereas as TSC patients without ASD had imaging values comparable to controls ${ }^{53}$. Graph theory based analysis of functional networks via EEG indicated a globally decreased functional connectivity in individuals with TSC irrespective of the presence of ASD, while individuals with non-syndromic ASD had a more complex pattern with decreased long- over short range connectivity and increased network resilience ${ }^{66}$.

Dysregulated mTOR signaling is not only involved in TSC. Other monogenic causes of ASD, including mutations of NF1 (neurofibromin 1), PTEN (phosphatase and tensin homolog), the tyrosine kinase MET and eIF4e are all involved in the mTOR signaling pathway ${ }^{67}$, raising the question whether dysregulation of the TSC/mTOR pathway predisposes to autism. This opens up exciting potential therapeutic options for the future, as mTOR inhibitors are already available and approved for other manifestations of TSC. 


\section{Therapeutic approaches}

Neurologic symptoms such as epilepsy, ASD, cognitive and behavioral problems remain an area of great worry for parents of children with TSC. Despite the presence of many antiepileptic drugs on the market, seizures in TSC can be devastating and difficult to control, and there is an association between early seizure onset and worse developmental outcome in TSC. Translational research has laid the foundation for promising therapeutic approaches. Rapamycin (Sirolimus), a compound originally identified from S. hygroscopicus on Easter Island (Rapa Nui gave the compound its name) and used as an immunosuppressant after kidney transplantations for many years, inhibits mTORC1, but not mTORC2 activity. mTOR inhibitors have been used in murine TSC models, and resulted in improved myelination and cytopathologic architecture, as well as restoration of synaptic function $56,61,68,69$, suggesting its potential to prevent development or progression of neurologic symptoms. Rapamycin treatment prolonged survival and prevented epilepsy in mice with a glial or a neural progenitor $T s c l$ deletion when initiated early in life, and caused cessation of seizures when initiated after seizure onset ${ }^{56,70,71}$. In addition, rapamycin treatment of mice with a neural stem cell $T s c 1$ deletion reduced anxiety ${ }^{72}$. Rapamycin also reverted the autism-like phenotype in cerebellar PC Tscl-knockout mice, prevented social deficits in $T s c 2$-knockout mice ${ }^{64,65}$, and reversed learning deficits in $T s c 2^{+/-}$mice ${ }^{61}$.

Sirolimus (rapamycin) and everolimus (a rapamycin analogue) have successfully been used to treat renal angiomyolipomas and SEGAs in studies in TSC patients. Everolimus recently received FDA approval for treatment of SEGAs at any age, and for renal anigiomyolipomas over the age of 18. Sirolimus also reduced lymphangioleiomyoma growth in some, but not all patients ${ }^{73-75}$. Interestingly, patients treated with everolimus for SEGAs had a clinically relevant reduction of their seizure frequency and an improved quality of life, but no changes in cognition, which was assessed as a secondary study outcome ${ }^{75}$. Subgroup analysis of this study revealed improved FA measures as a marker for white matter integrity on DTI imaging in everolimus-treated patients ${ }^{76}$. Recently the first prospective phase I/II trial was published that assessed the effect of everolimus on seizures as a primary outcome in 20 TSC patients with refractory epilepsy. 12 weeks (4 weeks titration, 8 weeks maintenance) of treatment resulted in a statistically significant reduction of seizure frequency and duration, with $20 \%$ of enrolled patients achieving seizure freedom, as well as an increased quality of life and improved behaviors, as reported by parents using the Nisonger Child Behavior Rating Form (NCBRF) and the Quality of Life for Children with Epilepsy (QOLCE) survey ${ }^{77}$. A randomized, placebo-controlled phase II study assessing the effect of everolimus on neurocognition as a primary outcome, with effects on seizures, sleep, ASD, behavior and academic skills as secondary outcomes, is currently recruiting patients (clinicaltrials.gov/show/NCT01289912).

Taken together, inhibition of the mTOR pathway with rapamycin or rapamycin analogues has been shown to be effective in murine models of TSC, and has promising first results regarding seizure control in patients with TSC. As mentioned above, a phase II study to assess effects on other neurologic complications is currently being conducted, but there is a long and winding road ahead, and many questions still need to be answered. We currently do not know why a TSC mutation causes severe neurologic impairment in one patient, but not in others, and what factors might be contributing. It has been shown that early-onset and refractory seizures are associated with worse developmental outcome, indicating that infancy is a critical period for the course of the disease. This opens up the question of whether the time of treatment initiation is crucial, and whether there might be a possibility to treat preventively. If so, how would we decide on whom to treat preventively given the wide spectrum of disease manifestations? Will a short-term treatment be sufficient, or do patients require long-term courses and potentially develop side more effects? Will patients with 
"mild" disease profit the same way as those who are severely affected, and vice versa? Having surrogate markers that predict response to treatment will be extremely helpful, and investigations are in progress to develop such biomarkers.

Nevertheless, seizures, cognitive and behavioral problems greatly determine disease burden in TSC. Conventional therapies are often insufficient to control them, as they do not address the underlying mechanism. The prospect of being able to pursue a mechanism-based treatment approach for neurologic manifestations of TSC is a promising and exciting possibility, and we hope, will contribute to help patients and their families in the future to improve their quality of life.

\section{References}

1. Northrup H, Krueger T. Tuberous sclerosis complex diagnostic critera update: recommendations of the 2012 international tuberous sclerosis complex consensus conference. Pediatric Neurology. 2013; 49:243-254. [PubMed: 24053982]

2. European Chromosome 16 Tuberous Sclerosis Consortium. Identification and characterization of the tuberous sclerosis gene on chromosome 16. Cell. 1993; 75(7):1305-1315. [PubMed: 8269512]

3. Slegtenhorst MV, de Hoogt R, Hermans C, et al. Identification of the Tuberous Sclerosis Gene TSC1 on Chromosome 9q34. Science. 1997; 277(5327):805-808. [PubMed: 9242607]

4. Curatolo P, Bombardieri R, Jozwiak S. Tuberous sclerosis. Lancet. 2008; 372(9639):657-668. [PubMed: 18722871]

5. Au KS, Ward CH, Northrup H. Tuberous sclerosis complex: disease modifiers and treatments. Current opinion in pediatrics. 2008; 20(6):628-633. [PubMed: 19005330]

6. Richardson E. Pathology of Tuberous Sclerosis. Annals of the New York Academy of Sciences. 1991; 615:128-139. [PubMed: 2039138]

7. Mizuguchi M, Takashima S. Neuropathology of tuberous sclerosis. Brain \& development. 2001; 23(7):508-515. [PubMed: 11701246]

8. Ess KC, Kamp C, Tu BP, Gutmann DH. Developmental origin of subependymal giant cell astrocytoma in tuberous sclerosis complex. Neurology. 2005; 64(8):1446-1449. [PubMed: 15851742]

9. Kaczorowska M, Jurkiewicz E, Domańska-Pakieła D, et al. Cerebral tuber count and its impact on mental outcome of patients with tuberous sclerosis complex. Epilepsia. 2011; 52(1):22-27. [PubMed: 21204819]

10. Zhou J, Shrikhande G, Xu J, et al. Tsc1 mutant neural stem / progenitor cells exhibit migration deficits and give rise to subependymal lesions in the lateral ventricle. Genes \& Development. 2011; 25(15):1595-1600. [PubMed: 21828270]

11. Curatolo P, JóŸwiak S, Nabbout R. Management of epilepsy associated with tuberous sclerosis complex (TSC): Clinical recommendations. European Journal of Paediatric Neurology. 2012; 16(6):582-586. [PubMed: 22695035]

12. Holmes GL, Stafstrom CE. Tuberous sclerosis complex and epilepsy: recent developments and future challenges. Epilepsia. 2007; 48(4):617-630. [PubMed: 17386056]

13. Major P, Rakowski S, Simon MV, et al. Are cortical tubers epileptogenic? Evidence from electrocorticography. Epilepsia. 2009; 50(1):147-154. [PubMed: 19125835]

14. Gallagher A, Chu-Shore CJ, Montenegro M, et al. Associations between electroencephalographic and magnetic resonance imaging findings in tuberous sclerosis complex. Epilepsy research. 2009; 87(2-3):197-202. [PubMed: 19783123]

15. Curatolo P, Verdecchia M, Bombardieri R. Vigabatrin for tuberous sclerosis complex. Brain \& Development. 2001; 23:649-653. [PubMed: 11701271]

16. Zhang B, McDaniel SS, Rensing NR, Wong M. Vigabatrin Inhibits Seizures and mTOR Pathway Activation in a Mouse Model of Tuberous Sclerosis Complex. PLoS ONE. 2013; 8(2):e57445. [PubMed: 23437388] 
17. De Vries P, Humphrey A, McCartney D, Prather P, Bolton P, Hunt A. Consensus clinical guidelines for the assessment of cognitive and behavioural problems in Tuberous Sclerosis. European child \& adolescent psychiatry. 2005; 14(4):183-190. [PubMed: 15981129]

18. Gillberg I, Gillberg C, Ahlsen G. Autistic behaviour and attention deficits in tuberous sclerosis: a population-based study. Dev Med Child Neurol. 1994; 36(1):50-56. [PubMed: 8132114]

19. D'Agati E, Moavero R, Cerminara C, Curatolo P. Attention-deficit hyperactivity disorder (ADHD) and tuberous sclerosis complex. Journal of child neurology. 2009; 24(10):1282-1287. [PubMed: 19805824]

20. Wernicke JF, Holdridge KC, Jin L, et al. Seizure risk in patients with attention-deficithyperactivity disorder treated with atomoxetine. Developmental medicine and child neurology. 2007; 49(7):498-502. [PubMed: 17593120]

21. Muzykewicz D, Newberry P, Danforth N, Halpern EF, Thiele E. Psychiatric comorbid conditions in a clinic population of 241 patients with tuberous sclerosis complex. Epilepsy \& behavior: E\&B. 2007; 11(4):506-513.

22. Pulsifer MB, Winterkorn EB, Thiele E. Psychological profile of adults with tuberous sclerosis complex. Epilepsy \& behavior: E\&B. 2007; 10(3):402-406.

23. Raznahan, Joinson C, O'Callaghan F, Osborne JP, Bolton PF. Psychopathology in tuberous sclerosis: an overview and findings in a population-based sample of adults with tuberous sclerosis. Journal of intellectual disability research: JIDR. 2006; 50(8):561-569. [PubMed: 16867063]

24. Joinson C, O'Callaghan FJ, Osborne JP, Martyn C, Harris T, Bolton PF. Learning disability and epilepsy in an epidemiological sample of individuals with tuberous sclerosis complex. Psychological Medicine. 2003; 33(2):335-344. [PubMed: 12622312]

25. Eeghen AM, Van Numis AI, Staley BA, Therrien SE, Ronald L, Thiele EA. Characterizing sleep disorders of adults with tuberous sclerosis complex: a questionnaire-based study and review. Epilepsy \& behavior: E\&B. 2012; 20(1):68-74.

26. Chu-shore CJ, Major P, Camposano S, Muzykewicz D, Thiele EA. The natural history of epilepsy in tuberous sclerosis complex. Epilepsia. 2011; 51(7):1236-1241. [PubMed: 20041940]

27. Hunt A, Stores G. Sleep disorder and epilepsy in children with tuberous sclerosis: a questionnairebased study. Dev Med Child Neurol. 1994; 36(2):108-115. [PubMed: 7510655]

28. Bruni O, Cortesi F, Giannotti F, Curatolo P. Sleep disorders in tuberous sclerosis: a polysomnographic study. Brain \& development. 1995; 17(1):52-56. [PubMed: 7762764]

29. Geschwind DH, Levitt P. Autism spectrum disorders: developmental disconnection syndromes. Current opinion in neurobiology. 2007; 17(1):103-111. [PubMed: 17275283]

30. Belmonte MK, Allen G, Beckel-Mitchener A, Boulanger LM, Carper Ra, Webb SJ. Autism and abnormal development of brain connectivity. The Journal of neuroscience: the official journal of the Society for Neuroscience. 2004; 24(42):9228-9231. [PubMed: 15496656]

31. Hoeffer CA, Klann E. mTOR signaling: at the crossroads of plasticity, memory and disease. Trends in Neurosciences. 2011; 33(2):1-17.

32. Fingar DC, Salama S, Tsou C, Harlow E, Blenis J. Mammalian cell size is controlled by mTOR and its downstream targets S6K1 and 4EBP1 / eIF4E. Genes \& Development. 2002; 16(12):14721487. [PubMed: 12080086]

33. Holz MK, Ballif B, Gygi SP, Blenis J. mTOR and S6K1 mediate assembly of the translation preinitiation complex through dynamic protein interchange and ordered phosphorylation events. Cell. 2005; 123(4):569-580. [PubMed: 16286006]

34. Guertin D, Stevens DM, Thoreen CC, et al. Ablation in mice of the mTORC components raptor, rictor, or mLST8 reveals that mTORC2 is required for signaling to Akt-FOXO and PKCalpha, but not S6K1. Developmental cell. 2006; 11(6):859-871. [PubMed: 17141160]

35. Huang J, Wu S, Wu C-L, Manning BD. Signaling events downstream of mammalian target of rapamycin complex 2 are attenuated in cells and tumors deficient for the tuberous sclerosis complex tumor suppressors. Cancer research. 2009; 69(15):6107-6114. [PubMed: 19602587]

36. Laplante M, Sabatini DM. mTOR signaling in growth control and disease. Cell. 2012; 149(2):274293. [PubMed: 22500797] 
37. Schick V, Majores M, Engels G, et al. Differential Pi3K-pathway activation in cortical tubers and focal cortical dysplasias with balloon cells. Brain pathology. 2007; 17(2):165-173. [PubMed: 17388947]

38. Jansen FE, Notenboom RGE, Nellist M, et al. Differential localization of hamartin and tuberin and increased S6 phosphorylation in a tuber. Neurology. 2004; 63(7):1293-1295. [PubMed: 15477556]

39. Baybis M, Yu J, Lee A, et al. mTOR cascade activation distinguishes tubers from focal cortical dysplasia. Annals of neurology. 2004; 56(4):478-487. [PubMed: 15455405]

40. Haddad, La; Smith, N.; Bowser, M., et al. The TSC1 tumor suppressor hamartin interacts with neurofilament- $\mathrm{L}$ and possibly functions as a novel integrator of the neuronal cytoskeleton. The Journal of biological chemistry. 2002; 277(46):44180-44186. [PubMed: 12226091]

41. Choi Y, Nardo A, Di Kramvis I, et al. Tuberous sclerosis complex proteins control axon formation. Genes \& Development. 2008; 22(18):2485-2495. [PubMed: 18794346]

42. Brown HLD, Kaun KR, Edgar B. The Small GTPase Rheb Affects Central Brain Neuronal Morphology and Memory Formation in Drosophila. PLoS ONE. 2012; 7(9):e44888. [PubMed: 23028662]

43. Martin KC. Local protein synthesis during axon guidance and synaptic plasticity. Current opinion in neurobiology. 2004; 14(3):305-310. [PubMed: 15194110]

44. Nie D, Nardo A, Di Han JM, et al. Tsc2-Rheb signaling regulates EphA-mediated axon guidance. Nature Neuroscience. 2010; 13(2):163-172.

45. Knox S, Ge H, Dimitroff BD, et al. Mechanisms of TSC-mediated control of synapse assembly and axon guidance. PloS one. 2007; 2(4):e375. [PubMed: 17440611]

46. Garaci FG, Floris R, Bozzao A, et al. Increased brain apparent diffusion coefficient in tuberous sclerosis. Radiology. 2004; 232(2):461-465. [PubMed: 15215545]

47. Peng SS-F, Lee W-T, Wang YH, Huang K-M. Cerebral diffusion tensor images in children with tuberous sclerosis: a preliminary report. Pediatric radiology. 2004; 34(5):387-392. [PubMed: 15029464]

48. Luat AF, Makki M, Chugani HT. Neuroimaging in tuberous sclerosis complex. Current opinion in neurology. 2007; 20(2):142-150. [PubMed: 17351483]

49. Arulrajah S, Ertan G, Jordan L, et al. Magnetic resonance imaging and diffusion-weighted imaging of normal-appearing white matter in children and young adults with tuberous sclerosis complex. Neuroradiology. 2009; 51(11):781-786. [PubMed: 19603155]

50. Widjaja E, Simao G, Mahmoodabadi SZ, et al. Diffusion tensor imaging identifies changes in normal-appearing white matter within the epileptogenic zone in tuberous sclerosis complex. Epilepsy research. 2010; 89(2-3):246-253. [PubMed: 20129760]

51. Krishnan ML, Commowick O, Jeste SS, et al. Diffusion features of white matter in tuberous sclerosis with tractography. Pediatric neurology. 2010; 42(2):101-106. [PubMed: 20117745]

52. Simao G, Raybaud C, Chuang S, Go C, Snead OC, Widjaja E. Diffusion tensor imaging of commissural and projection white matter in tuberous sclerosis complex and correlation with tuber load. AJNR. American journal of neuroradiology. 2010; 31(7):1273-1277. [PubMed: 20203114]

53. Peters JM, Sahin M, Vogel-Farley VK, et al. Loss of White Matter Microstructural Integrity Is Associated with Adverse Neurological Outcome in Tuberous Sclerosis Complex. Academic Radiology. 2012; 19(1):17-25. [PubMed: 22142677]

54. Meikle L, Talos DM, Onda H, et al. A mouse model of tuberous sclerosis: neuronal loss of Tsc1 causes dysplastic and ectopic neurons, reduced myelination, seizure activity, and limited survival. The Journal of neuroscience: the official journal of the Society for Neuroscience. 2007; 27(21): 5546-5558. [PubMed: 17522300]

55. Way SW, McKenna J, Mietzsch U, Reith RM, Wu HC-J, Gambello MJ. Loss of Tsc2 in radial glia models the brain pathology of tuberous sclerosis complex in the mouse. Human molecular genetics. 2009; 18(7):1252-1265. [PubMed: 19150975]

56. Carson RP, Van Nielen DL, Winzenburger P, Ess KC. Neuronal and glia abnormalities in Tsc1deficient forebrain and partial rescue by rapamycin. Neurobiology of disease. 2012; 45(1):369380. [PubMed: 21907282] 
57. Tang SJ, Reis G, Kang H, Gingras A-C, Sonenberg N, Schuman EM. A rapamycin-sensitive signaling pathway contributes to long-term synaptic plasticity in the hippocampus. Proceedings of the National Academy of Sciences of the United States of America. 2002; 99(1):467-472. [PubMed: 11756682]

58. Von der Brelie C, Waltereit R, Zhang L, Beck H, Kirschstein T. Impaired synaptic plasticity in a rat model of tuberous sclerosis. The European journal of neuroscience. 2006; 23(3):686-692. [PubMed: 16487150]

59. Waltereit R, Japs B, Schneider M, de Vries P, Bartsch D. Epilepsy and Tsc2 haploinsufiiciency lead to autistic-like social deficit behaviors on rats. Behavioral Genetics. 2011; 41(3):364-372.

60. Bateup HS, Takasaki KT, Saulnier JL, Denefrio CL, Sabatini BL. Loss of Tsc1 in vivo impairs hippocampal mGluR-LTD and increases excitatory synaptic function. The Journal of neuroscience: the official journal of the Society for Neuroscience. 2011; 31(24):8862-8869. [PubMed: 21677170]

61. Ehninger D, Han S, Shilyansky C, et al. Reversal of learning deficits in a Tsc2+/- mouse model of tuberous sclerosis. Nature medicine. 2008; 14(8):843-848.

62. Goorden SMI, van Woerden GM, van der Weerd L, Cheadle JP, Elgersma Y. Cognitive deficits in Tsc1+/- mice in the absence of cerebral lesions and seizures. Annals of neurology. 2007; 62(6): 648-655. [PubMed: 18067135]

63. Chévere-Torres I, Maki JM, Santini E, Klann E. Impaired social interactions and motor learning skills in tuberous sclerosis complex model mice expressing a dominant/negative form of tuberin. Neurobiology of disease. 2012; 45(1):156-164. [PubMed: 21827857]

64. Tsai PT, Hull C, Chu Y, et al. Autistic-like behaviour and cerebellar dysfunction in Purkinje cell Tsc1 mutant mice. Nature. 2012; 488(7413):647-651. [PubMed: 22763451]

65. Reith RM, McKenna J, Wu H, et al. Loss of Tsc2 in Purkinje cells is associated with autistic-like behavior in a mouse model of tuberous sclerosis complex. Neurobiology of disease. 2013; 51:93103. [PubMed: 23123587]

66. Peters JM, Taquet M, Vega C, et al. Brain functional networks in syndromic and non-syndromic autism: a graph theoretical study of EEG connectivity. BMC medicine. 2013; 11(1):54. [PubMed: 23445896]

67. Schaaf CP, Zoghbi HY. Solving the autism puzzle a few pieces at a time. Neuron. 2011; 70(5): 806-808. [PubMed: 21658575]

68. Meikle L, Pollizzi K, Egnor A, et al. Response of a neuronal model of tuberous sclerosis to mammalian target of rapamycin (mTOR) inhibitors: effects on mTORC1 and Akt signaling lead to improved survival and function. The Journal of neuroscience: the official journal of the Society for Neuroscience. 2008; 28(21):5422-5432. [PubMed: 18495876]

69. Way SW, Rozas NS, Wu HC, et al. The differential effects of prenatal and/or postnatal rapamycin on neurodevelopmental defects and cognition in a neuroglial mouse model of tuberous sclerosis complex. Human molecular genetics. 2012; 21(14):3226-3236. [PubMed: 22532572]

70. Zeng L-H, Xu L, Gutmann DH, Wong M. Rapamycin prevents epilepsy in a mouse model of tuberous sclerosis complex. Annals of neurology. 2008; 63(4):444-453. [PubMed: 18389497]

71. Goto J, Talos DM, Klein P, et al. Regulable neural progenitor-specific Tsc1 loss yields giant cells with organellar dysfunction in a model of tuberous sclerosis complex. Proceedings of the National Academy of Sciences of the United States of America. 2011; 108(45):E1070-E1079. [PubMed: 22025691]

72. Cambiaghi M, Cursi M, Magri L, et al. Behavioural and EEG effects of chronic rapamycin treatment in a mouse model of Tuberous Sclerosis Complex. Neuropharmacology. 2012; 67C:1-7. [PubMed: 23159330]

73. Franz DN, Leonard J, Tudor C, et al. Rapamycin causes regression of astrocytomas in tuberous sclerosis complex. Annals of neurology. 2006; 59(3):490-498. [PubMed: 16453317]

74. Bissler JJ, McCormack FX, Young LR, et al. Sirolimus for angiomyolipoma in tuberous sclerosis complex or lymphangioleiomyomatosis. The New England journal of medicine. 2008; 358(2): 140-151. [PubMed: 18184959] 
75. Krueger D, Care MM, Holland K, et al. Everolimus for subependymal giant-cell astrocytomas in tuberous sclerosis. The New England journal of medicine. 2010; 363(19):1801-1811. [PubMed: 21047224]

76. Tillema J-M, Leach JL, Krueger D, Franz DN. Everolimus alters white matter diffusion in tuberous sclerosis complex. Neurology. 2012; 78(8):526-531. [PubMed: 22262746]

77. Krueger D, Wilfong A, Holland-Bouley K, et al. Everolimus treatment of refractory epilepsy in tuberous sclerosis complex. Annals of neurology. 2013 Epub ahead of print. 10.1002/ana.23960 

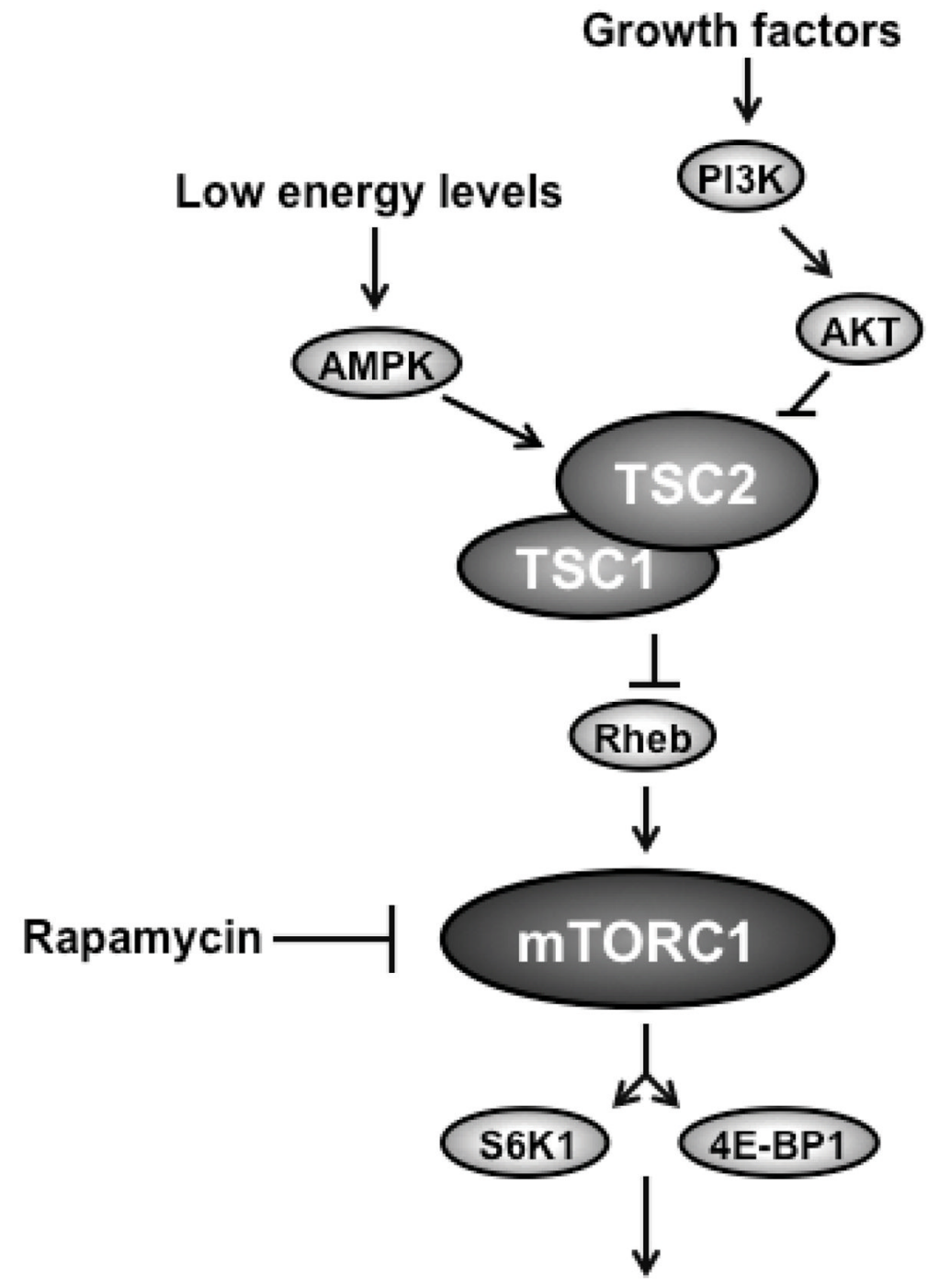

Translation initiation Cell growth control

Figure 1.

Schematic of the TSC/mTOR pathway. mTORC1 is activated by growth factors, hormones and nutrients, and regulates cell size and translation via its substrates S6K1 and 4E-BP1. The heterodimeric TSC1/TSC2 complex is activated through AMPK by low energy states and functions via Rheb to inhibit mTORC1 activity. The compound rapamycin inhibits mTORC 1 activity downstream of the TSC $1 / 2$ complex. 


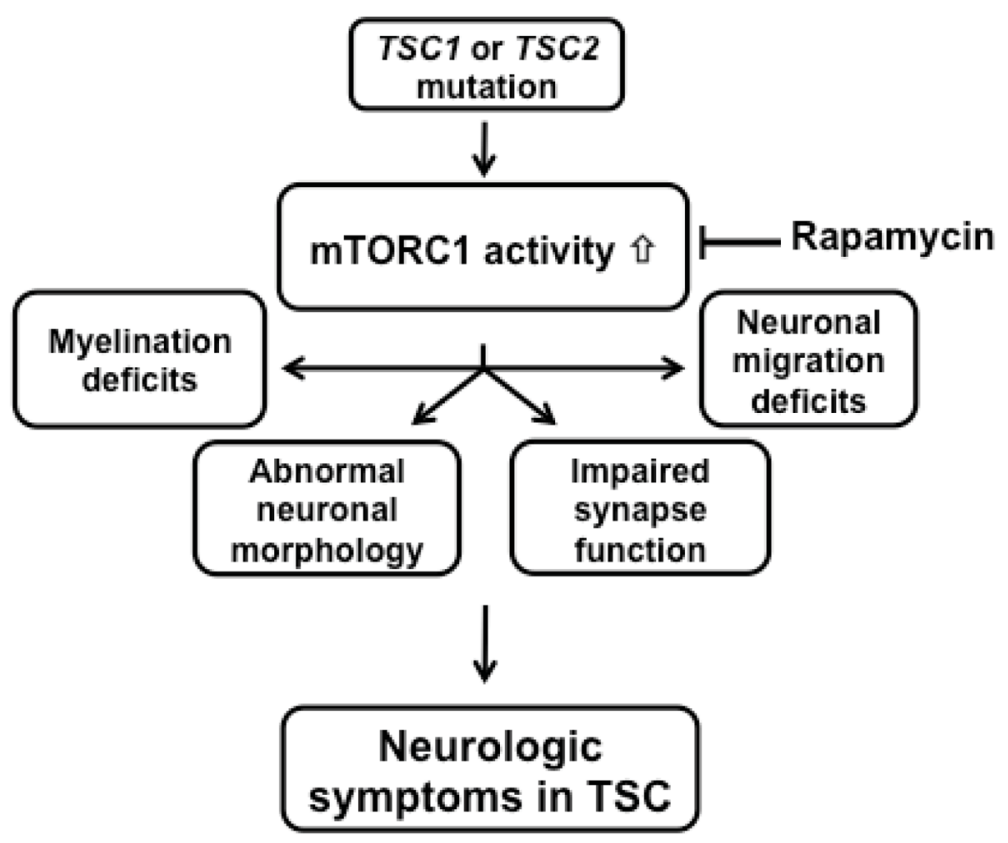

Figure 2.

Proposed model of TSC pathomechanism in the brain. Mutation of either TSC1 or TSC2 disrupts the inhibitory function of the TSC1/2 complex. This leads to constitutively increased mTORC1 activity, which in turn results in abnormal neuronal connectivity, characterized by abnormal neuronal morphology and migration, abnormal white matter and impaired synapse function. 